\title{
Extraction and Antioxidant Activity of Flavonoids from Seed Coat of Borassus flabellifer Linn using Orthogonal Array $\left(\mathbf{L 1 6}\left(4^{4}\right)\right)$
}

\author{
P. MUTHUKUMARAN*, T. SATHISHKUMAR, M. ALAMELUMANGAI, J. DHANALAKSHMI, M. MATHUMITHAAND \\ R. SARANYA RENGANAYAKI
}

Department of Biotechnology, Kumaraguru College of Technology, Coimbatore-641 049, India

\begin{abstract}
Muthukumaran, et al.: Flavonoid Extraction from Seed Coat of Borassus flabellifer by Orthogonal Array
This study aimed at optimizing the conditions required for maximal extraction of flavonoids from the seed coat of Borassus flabellifer and to evaluate antioxidant properties. Initially, the parameters like time, temperature, solvent concentration and material ratio were optimized using orthogonal design of experiments. Temperature was found to play a significant role in the maximum extraction of flavonoids and the optimum conditions were found to be $85^{\circ}, 3 \mathrm{~h}, 70 \%$ aqueous-ethanol and 1:20 material ratio. The crude samples were tested for antioxidant activity using the 1,1-diphenyl-2-picrylhydrazyl radical scavenging assay. Percent inhibition of the 1,1-diphenyl-2-picrylhydrazyl radical was found highest $(95 \%) \mathrm{at} 50 \mu \mathrm{g} / \mathrm{ml}$ concentration of the extract of seed coat of $\boldsymbol{B}$. flabellifer. Flavonoids were then purified using preparative thin layer chromatography. The purified sample did not reveal significant antioxidant activities. Hence, further purification of the sample is needed to obtain better results.
\end{abstract}

Key words: Antioxidant, seed coat, Borassus flabellifer, flavonoid, optimization

Since ancient times, plant products have been used to treat a variety of diseases as most of the bioactive compounds obtained from the plants appear to be less toxic to humans. Plant parts with medicinal importance are most commonly used for treatment of ailments such as cuts and wounds ${ }^{[1]}$. Those properties of many such plants remains unrevealed. One such plant is B. flabellifer, which belongs to family Arecaceae, commonly known as Palmyra palm or Asian toddy palm, a native of tropical Africa and widely distributed and cultivated in tropical Asian countries such as Thailand, Bangladesh, India, Myanmar, Sri Lanka and Malaysia $^{[2]}$. This tree is tall and erect, grows up to the height of $30 \mathrm{~m}$ and it has large fan shaped leaves of diameter 0.9 to $1.5 \mathrm{~m}$ with a black stem and crown of leaves at the top, palmately fan shaped, petiole edges with hard horny spinescent serratures; flowers unisexual, male spadix branched female spadix simple; fruits large, subglobose drupes, on the greatly enlarged perianth ${ }^{[3]}$. There are three most economical and important species of genus Borassus, such as B. aethiopum Mart, B. flabellifer Linn and B. sundaicus Becc $^{[4]}$.

*Address for correspondence E-mail:m.kumaran005@gmail.com

January-February 2018
Previous studies reported optimum conditions for the extraction of flavonoids from red raspberry fruits. Factors like temperature, time, material ratio and solvent concentration were considered for optimization. Extraction of flavonoids was carried out by altering each parameter to find optimal condition in which the extraction is maximum. Orthogonal design was employed and the optimum extraction conditions were determined calorimetrically. The extraction of flavonoids was maximum at $80^{\circ}$ for $3 \mathrm{~h}$ and the material ratio was 1:10 and $95 \%$ aqueousethanol was the solvent ${ }^{[5]}$. Similarly, extraction, purification and characterization of flavonoids from Opuntia milpa alta skin was also reported. The parameters for extraction (volume of solvent, solvent to material ratio, temperature and time for extraction) were optimized by the orthogonal design ${ }^{[6]}$.

This is an open access article distributed under the terms of the Creative Commons Attribution-NonCommercial-ShareAlike 3.0 License, which allows others to remix, tweak, and build upon the work non-commercially, as long as the author is credited and the new creations are licensed under the identical terms

Accepted 10 November 2017

Revised 05 April 2017

Received 29 September 2016

Indian J Pharm Sci 2018;80(1):46-51 
Optimization of these parameters was mainly done to maximize the yield of flavonoids. Previous studies reported that, optimization of extraction of phenolic compounds from cactus pear (Opuntiaficus indica) skin using response surface methodology. The extraction conditions, which have been optimized included time, temperature and solvent concentration. The extraction of phenolic compounds was found to be maximum at higher temperatures ${ }^{[7]}$.

Flavonoids were extracted and quantified from waste tobacco leaves. The sample was extracted with $70 \%$ aqueous-ethanol and then ethanol was evaporated at $50^{\circ}$ using a rotary evaporator. The extract was then subjected to thin layer chromatography (TLC) and column chromatography using various mobile phases. TLC was done on silica gel plates and the mobile phase used here was ethyl acetate:aqueousethanol:water (65:10:15). After the solvent has run to about the edge of the plates, they were examined under UV-light. The flavonoids were visualized as + spots and three types of flavonoids namely, apigenin, rutin and quercetin were isolated ${ }^{[8]}$. Previously, phytochemical analysis and antibacterial activity from the methanol extract of the seed coat of palmyra palm was studied. The phytochemical analysis showed that the extract contained various phytochemicals including flavonoids, and saponins ${ }^{[9]}$.

To evaluate the antioxidant potential of phytochemicals using 1,1-diphenyl-2-picrylhydrazyl (DPPH) method, the antioxidant activity of the given sample was determined based on the scavenging activity of stable radical chromogen $\mathrm{DPPH}^{[10]}$. Antioxidant assay of the aqueous-ethanol extract of the seed coat of B. flabellifer was determined using 2,2'-azino-bis3-ethylbenzthiazoline-6-sulphonic acid (ABTS) and DPPH radical scavenging method and ascorbic acid was used as a standard ${ }^{[11]}$. Similarly, free radical scavenging activities of the fruits of $B$. flabellifer were studied. Soxhlet extraction of the fruit was carried out with water, methanol, petroleum ether and chloroform. The antioxidant activity was estimated using DPPH and ABTS assay. The aqueous extracts of the fruits were also subjected to the phytochemical screening and it revealed the presence of flavonoids, tannins and saponins $^{[12]}$.

\section{MATERIALS AND METHODS}

The tender seeds of $B$. flabellifer were purchased from the local market, Coimbatore district, Tamil Nadu. The seed coats peeled from the seeds were washed with distilled water and then dried under shade. The shade dried seed coats were powdered and stored at room temperature $\left(28 \pm 2^{\circ}\right)$ in air tight plastic bags for solvent extraction. Ethanol, methanol, ethyl acetate, chloroform, heptane, acetone, $\mathrm{AlCl}_{3}, 5 \%$ sodium nitrite, $1 \mathrm{M}$ sodium hydroxide, glacial acetic acid, $6 \mathrm{M}$ sulphuric acid, $25 \mathrm{mM}$ disodium hydrogen phosphate, $4 \mathrm{mM}$ ammonium molybdate, ascorbic acid and quercetin were obtained from S. D. Fine-Chem Ltd., Mumbai, India. For TLC analysis, formic acid and silica gel $\mathrm{G}_{60}$ were obtained from Merck, Darmstadt, Germany. DPPH was obtained from HiMedia, India.

\section{Solvent extraction:}

The dried sample was extracted with aqueous-ethanol, acetone, chloroform and water. About $0.5 \mathrm{~g}$ of the sample was extracted with $25 \mathrm{ml}$ of these solvents in a shaker at $37^{\circ}$ and $100 \mathrm{rpm}$ overnight. The maximum yield of flavonoids was obtained with aqueous-ethanol extract.

\section{Estimation of flavonoids using $\mathrm{AlCl}_{3}$ method:}

The total flavonoid content present in the extract was quantified spectrophotometrically. Accurately measured $0.1 \mathrm{ml}$ of the extract was made up to $5 \mathrm{ml}$ using distilled water. To this, $0.3 \mathrm{ml}$ of $5 \% \mathrm{NaNO}_{2}$ was added and after $5 \mathrm{~min} 3 \mathrm{ml}$ of $10 \% \mathrm{AlCl}_{3}$ was added and mixed well. Finally, $2 \mathrm{ml}$ of $1 \mathrm{M} \mathrm{NaOH}$ was added after $6 \mathrm{~min}$ and absorbance was measured at $510 \mathrm{~nm}^{[13]}$. Quercetin was used as a standard for constructing the calibration curve.

\section{Optimization using orthogonal design:}

Orthogonal design is a kind of experimental design, which is similar like that of response surface methodology and Benken-Box design to identify the key variables that are responsible for the expected function. Optimization of flavonoid extraction for B. flabellifer has yet not been reported. In this, an orthogonal array $\left(\mathrm{L} 16\left(4^{4}\right)\right)$ was constructed to evaluate the effects of the following factors, temperature (A), time (B), material ratio (C), aqueous-ethanol concentration (D). Factors and experimental data are displayed in the Table 1 and 2. The data were analysed using Minitab 16.1 software.

\section{Identification of flavonoids by TLC:}

Flavonoids present in the crude extract were identified by TLC performed under the following conditions; adsorbent layer was silica gel 60, layer thickness $0.25 \mathrm{~mm}$, layer size $20 \times 10 \mathrm{~cm}$, glass chamber 
TABLE 1: ORTHOGONAL DESIGN - FACTORS AND LEVELS

\begin{tabular}{lcccc}
\hline \multirow{2}{*}{ Factors } & \multicolumn{4}{c}{ Levels } \\
\cline { 2 - 5 } & $\mathbf{1}$ & $\mathbf{2}$ & $\mathbf{3}$ & $\mathbf{4}$ \\
\hline Temperature (A) & $55^{\circ}$ & $65^{\circ}$ & $75^{\circ}$ & $85^{\circ}$ \\
Time (B) & $1 \mathrm{~h}$ & $2 \mathrm{~h}$ & $3 \mathrm{~h}$ & $4 \mathrm{~h}$ \\
Material ratio (C) & $01: 05$ & $01: 10$ & $01: 15$ & $01: 20$ \\
Aqueous ethanol & $65 \%$ & $70 \%$ & $75 \%$ & $80 \%$ \\
concentration (D) & & &
\end{tabular}

\section{TABLE 2: ORTHOGONAL DESIGN AND EXPERIMENTAL RESULTS}

\begin{tabular}{cccccc}
\hline No. & $\begin{array}{c}\text { Temperature Time } \\
\text { (A) }\end{array}$ & (B) & $\begin{array}{c}\text { Material } \\
\text { ratio } \\
\text { (C) }\end{array}$ & $\begin{array}{c}\text { Aqueous ethanol } \\
\text { concentration } \\
\text { (D) }\end{array}$ & $\begin{array}{c}\text { Yield } \\
\text { (mg/g) }\end{array}$ \\
\hline 1 & 1 & 1 & 1 & 1 & 1.62 \\
2 & 1 & 2 & 2 & 2 & 1.1 \\
3 & 1 & 3 & 3 & 3 & 0.74 \\
4 & 1 & 4 & 4 & 4 & 0.96 \\
5 & 2 & 1 & 3 & 2 & 1.31 \\
6 & 2 & 2 & 4 & 1 & 0.46 \\
7 & 2 & 3 & 1 & 4 & 0.48 \\
8 & 2 & 4 & 2 & 3 & 1.52 \\
9 & 3 & 1 & 4 & 3 & 1.95 \\
10 & 3 & 2 & 3 & 4 & 2.19 \\
11 & 3 & 3 & 2 & 1 & 1.73 \\
12 & 3 & 4 & 1 & 2 & 1.86 \\
13 & 4 & 1 & 2 & 4 & 4.24 \\
14 & 4 & 2 & 1 & 3 & 1.56 \\
15 & 4 & 3 & 4 & 2 & 6.73 \\
16 & 4 & 4 & 3 & 1 & 5.33 \\
\hline
\end{tabular}

$25 \times 25 \times 14 \mathrm{~cm}$, ascending separation technique, minimum $2 \mathrm{~h}$ chamber saturation state, length of run was $10 \mathrm{~cm}$, solvent composition- ethyl acetate:glacial acetic acid:formicacid:water (100:11:11:26), margin between start point and plate edge: $2.0 \mathrm{~cm}$ above the lower edge of the plate and $1.5 \mathrm{~cm}$ was left from each side, samples were applied as spots using capillary tubes, quercetin as a standard. After completion of the solvent run, plates were examined under ultraviolet light (254 and $365 \mathrm{~nm}$ ) for fluorescent spots to identify the flavonoids ${ }^{[13]}$.

\section{Isolation and purification of flavonoids by preparative TLC (PTLC):}

PTLC was carried out in a similar manner as TLC using glass plates $(20 \times 20 \mathrm{~cm})$ thickly coated with silica gel of $2 \mathrm{~mm}$. Quercetin was used as the standard. After the solvent has reached a particular distance, the plate was dried and viewed under ultraviolet light for fluorescent spots, which indicate the flavonoids. The fluorescent spots coinciding with the standard quercetin were marked and scrapped off along with the silica gel. The powder was reconstituted in phosphate buffer $(\mathrm{pH} 7)$, followed by centrifugation at $10000 \mathrm{rpm}$ for $10 \mathrm{~min}$. This step was carried out twice to ensure the complete removal of the adsorbent. The supernatant was then stored in sterile glass vials under refrigeration.

\section{In vitro antioxidant capacity assays:}

Total antioxidant capacity assay is based on the principle of reduction of molybdenum (VI) to molybdenum (V) by the extract and the subsequent formation of green phosphate/molybdenum complex at acid $\mathrm{pH}$ $0.1 \mathrm{ml}$ of the extracts of different concentrations $(10-50 \mu \mathrm{g} / \mathrm{ml})$ was prepared by dissolving appropriate volume of the extract in aqueous-ethanol. To all the tubes, $1 \mathrm{ml}$ of the reagent solution was added. The tubes were capped with aluminium foil and incubated at $95^{\circ}$ for $90 \mathrm{~min}$. The tubes were then cooled to room temperature and the absorbance was measured at $695 \mathrm{~nm}$ against a blank. Ascorbic acid was used as standard ${ }^{[14]}$. The total antioxidant capacity was expressed as ascorbic acid equivalent using the formula: ascorbic acid equivalent $(\mu \mathrm{M} / \mathrm{g})=(\mathrm{T} / \mathrm{S}) \times \mathrm{C} \times(\mathrm{V} / \mathrm{P}) \times$ $(\mathrm{RS} / \mathrm{E}) \times(1 \times \mathrm{MW})$, where, $\mathrm{T}=\mathrm{OD}$ of test solution, $\mathrm{S}=\mathrm{OD}$ of standard, $\mathrm{C}=$ concentration of test $(\mu \mathrm{g}), \mathrm{V}=$ volume of solvent used for extraction $(\mathrm{ml}), \mathrm{P}=$ amount of powder $(\mathrm{g}), \mathrm{RS}=$ volume of reagent solution $(\mathrm{ml}), \mathrm{E}=$ volume of extract $(\mathrm{ml}), \mathrm{MW}=$ molecular weight of ascorbic acid (176.13 g/g mol).

\section{Determination of DPPH radical scavenging activity:}

DPPH scavenging activity was measured by the slightly modified spectrophotometric method. The principle of this method is that DPPH radical is scavenged by antioxidants through the donation of protons forming reduced DPPH. The electrons become paired off and the solution loses colour depending on the number of electrons taken up. The colour changes from purple to yellow after reduction and the antioxidant activity is estimated by the decrease of absorbance at $517 \mathrm{~nm}^{[15]}$. The extracts of different concentrations $(10-50 \mu \mathrm{g} / \mathrm{ml})$ were prepared and the tubes were made up to $2 \mathrm{ml}$ with aqueous ethanol. The solution of DPPH in aqueous ethanol $(0.6 \mathrm{mM})$ was prepared fresh. To all the tubes, $0.5 \mathrm{ml}$ of the DPPH solution was added. The solution in the test tubes were mixed well and incubated in dark for $30 \mathrm{~min}$ at room temperature and absorbance was measured at $517 \mathrm{~nm}$. About $2 \mathrm{ml}$ of aqueous-ethanol mixed with $0.5 \mathrm{ml}$ of DPPH solution was taken as control. About $2 \mathrm{ml}$ of aqueous ethanol was taken as blank. The percentage inhibition of the radicals due to the antioxidant property of the extract was calculated 
using the formula: percent inhibition $=\left[\left(\mathrm{A}_{\text {control }}-\right.\right.$ $\left.\mathrm{A}_{\text {sample }} \mathrm{I} / \mathrm{A}_{\text {control }}\right] \times 100$.

\section{RESULTS AND DISCUSSION}

The flavonoid extraction in seed coat of $B$. flabellifer has the maximum yield of about $6.73 \mathrm{mg} / \mathrm{g}$. The optimal extraction condition for this yield were found as temperature $85^{\circ}\left(\mathrm{A}_{4}\right)$, time $3 \mathrm{~h}\left(\mathrm{~B}_{3}\right)$, material ratio 1:20 $\left(\mathrm{C}_{4}\right)$, aqueous ethanol concentration $70 \%\left(\mathrm{D}_{2}\right)$ i.e. $A_{4}>C_{4}>B_{3}>D_{2}$. The results were analysed in two and one way ANOVA and found that temperature is the significant variable for flavonoid extraction. Table 1 shows orthogonal design with factors and variable levels. The results of variable factors and levels were showed in Table 2.

The effect of temperature in the flavonoid yield was evaluated in the present study using four temperature settings at $55^{\circ}, 65^{\circ}, 75^{\circ}$ and $85^{\circ}$. Flavonoid yield gradually increased with the rise in temperature from $55^{\circ}$ to $85^{\circ}$. Temperature was proved to be a significant variable by analysis of one way and twoway ANOVA shown in fig. 1. The increase in flavonoid yield suggested that the diffusion rate of solvent and solubility of flavonoid increases with increasing temperature. Previous studies have also reported that increasing the temperature of solvent increased spreadabilty of the solute in the solvent as the viscosity and surface tension of the solvent reduced at higher temperatures $^{[13,16]}$.

Time is also one of the main factors affecting extraction. To achieve maximum yield, different extraction times were investigated. The optimal time duration for flavonoid extraction is found to be $3 \mathrm{~h}$ (fig. 2). This might be due to thermal degradation of flavonoid with

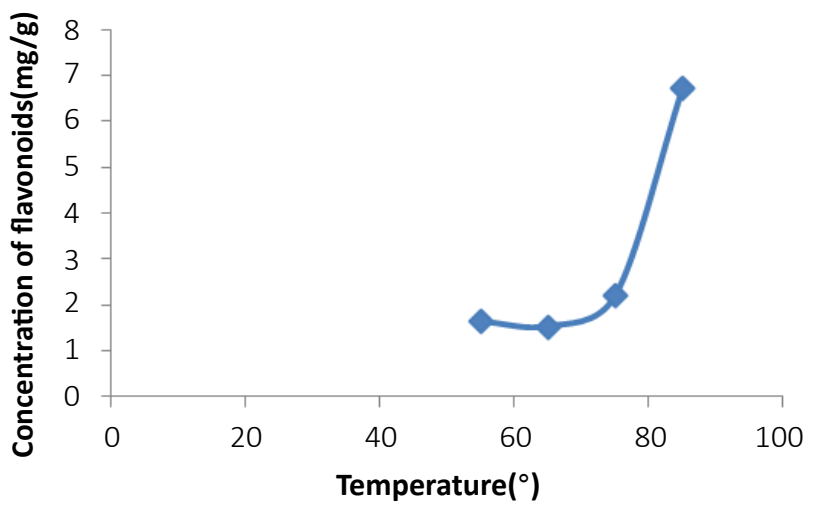

Fig. 1: Effect of temperature on extraction of flavonoids The flavonoid yield gradually increased with increasing temperature from $55^{\circ}$ to $85^{\circ}$. Temperature was found to be the significant variable by analysis of one way and two-way ANOVA

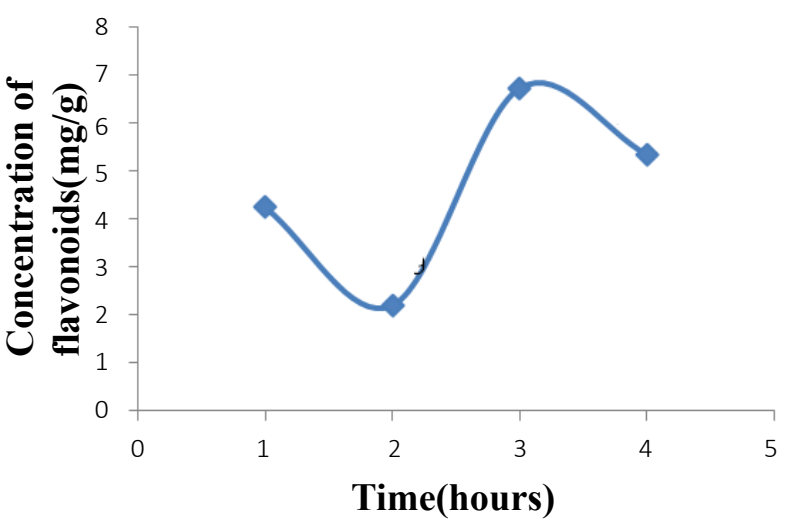

Fig. 2: Effect of time on extraction of flavonoids The optimal time duration for flavonoid extraction is found to be $3 \mathrm{~h}$

increase in time or because of the reduction of adhesion of flavonoids to the walls of glass tubes, which hinder the extraction process. Similar results revealed that the optimized time duration is well associated with the previous investigation ${ }^{[13]}$.

The flavonoid extraction from the $B$. flabellifer was maximum at 1:20 material ratio. This may be because when the solvent volume increased, excessive diffusion of solvent causes swelling of plant cells creating pores so that more flavonoids get extracted out from the cell. Previous investigation reported that when more solvent was used, faster extraction rate could be obtained ${ }^{[17]}$. This is because there is an increase in the concentration difference inside the plant cell and external solvent, which allowed more solvent to diffuse into the cell causing maximum flavonoid extraction. Fig. 3 shows material ratio on extraction of flavonoid from seed coat of $B$. flabellifer.

Aqueous ethanol of different strengths due to varying polarity is likely to extract different flavonoid contents. Flavonoid extraction was found to be maximum with $70 \%$ aqueous ethanol, however, with higher or lower alcohol strengths than $70 \%$ lower yields of flavonoids were obtained. Previous studies reported that extraction is maximum at $50 \%$ aqueous ethanol concentration $^{[17]}$. The reason for this is that aqueous ethanol being a polar solvent, water present can absorb heat energy facilitating heat transfer through the system and increasing extracting efficiency. Furthermore, the reason for maximum extraction is that flavonoid has low polarity with aqueous ethanol having high affinity to solubilize it. Fig. 4 shows effect of aqueous ethanol concentration in flavonoid yield.

On observing the TLC and PTLC plates under ultraviolet light, the fluorescent spots of the sample, 
which coincided with that of the standard quercetin were observed. The retention factor $R_{f}$ value of the standard (0.95) matched with the $\mathrm{R}_{\mathrm{f}}$ value of the sample (0.93). This revealed the presence of flavonoids in the crude sample. $R_{f}$ was calculated as the distance travelled by the compound to that by the solvent ${ }^{[18]}$. The regions in the plate where the flavonoids were present were scraped off along with the silica gel and then centrifuged with phosphate buffer $(\mathrm{pH} 7)$ at $10000 \mathrm{rpm}$ for $10 \mathrm{~min}$. The supernatant was then lyophilized.

The free radical scavenging property of crude extract of B. flabellifer were assessed using DPPH method and the results were shown in fig. 5. The amount of DPPH radical decreased in the presence of crude extract. On increasing the concentration of extract $(10 \mu \mathrm{g}$ to $50 \mu \mathrm{g}$ ), the percent inhibition increased from 80.42 to 93.23. The data obtained reveal that the extracts are free radical inhibitors and thus contain a potent antioxidant.

In previous studies, methanol extracts of the bark exhibited maximum inhibition of $77 \%$ at the

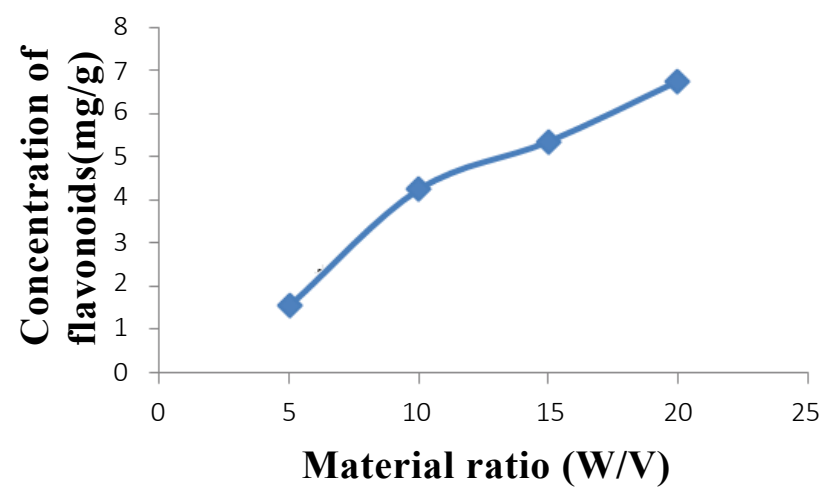

Fig. 3: Effect of material ratio on extraction of flavonoids The flavonoid extraction from the $B$. flabellifer was maximum at 1:20 material ratio

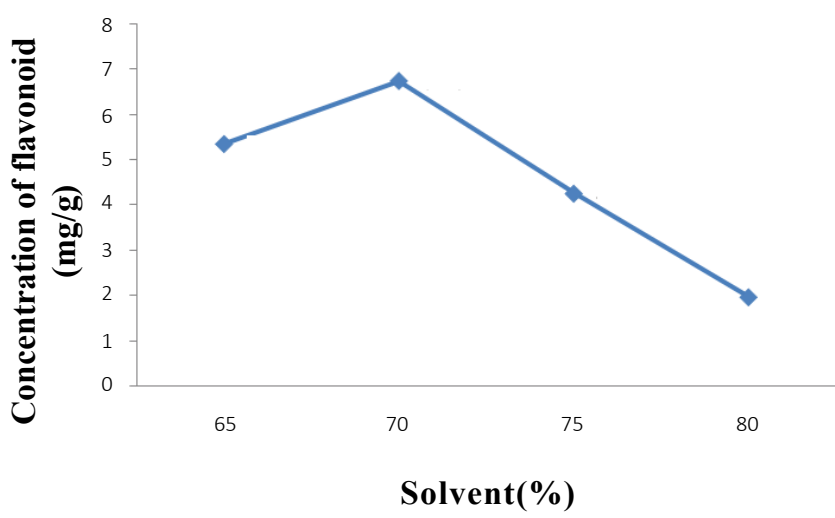

Fig.4: Effect of solvent (\%) on extraction of flavonoids The flavonoid extraction was maximum at $70 \%$ aqueous ethanol; at higher or lower concentration the yield was suppressed

January-February 2018

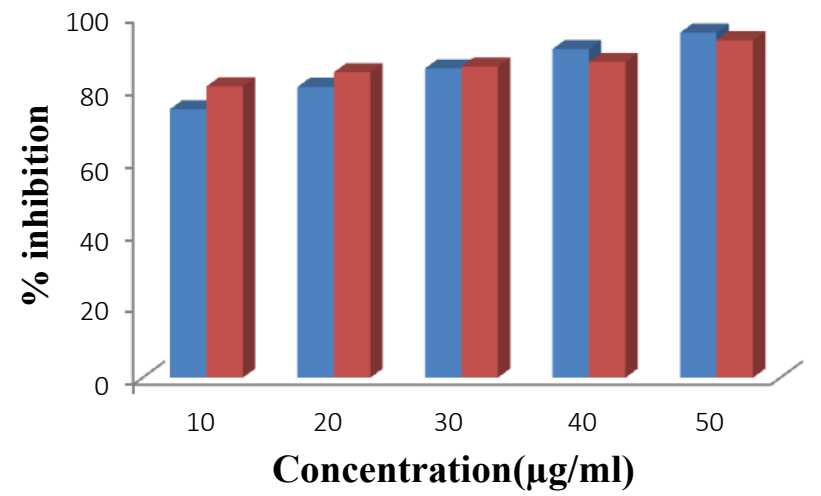

Fig. 5: Antioxidant activity of aqueous-ethanol extract by DPPH radical scavenging method

- Ascorbic acid; n crude extract

concentration of $900 \mu \mathrm{g} / \mathrm{ml}^{[19]}$. In our present study the same percent inhibition was obtained at the low concentration of $10 \mu \mathrm{g} / \mathrm{ml}$. Also, the investigation made on the antioxidant property of $B$. flabellifer, aqueous extract of pulp exhibited inhibition of $40 \%$ at $100 \mu \mathrm{g} / \mathrm{ml}^{[12]}$. This may due to the presence of higher amounts of flavonoids in our crude extract or due to more flavonoid solubilizing capacity of aqueousethanol. Previous studies reported that the methanol extract of the seed coat of $B$. flabellifer exhibited $60 \%$ inhibition at $10 \mu \mathrm{g} / \mathrm{ml}$, which is 1.5 fold lower than the result obtained in the present investigation ( $80 \%$ inhibition at $10 \mu \mathrm{g} / \mathrm{ml}$ ). This might be due to the better optimization of flavonoid extraction by using orthogonal design than the conventional shake flask method $^{[11]}$.

This study concluded that the optimum conditions required for maximum flavonoid extraction from the seed coat of $B$. flabellifer are $85^{\circ}, 70 \%$ ethanol and material ratio of 1:20 for $3 \mathrm{~h}$. The presence of flavonoid was confirmed by TLC and it is further purified by PTLC. The crude extract was found to possess antioxidant property even at low concentration. This suggested the potent antioxidant potential in the extract. Further purification of the flavonoids present in the seed coat of $B$. flabellifer is needed, so that the seed coat could serve as a better source of this bioactive compound.

\section{Conflict of interest}

We declare that we have no conflict of interest.

Financial support and sponsorship:

Nil. 


\section{REFERENCES}

1. Awal A, Haq QN, Quaker MA, Ahmed M. Structural study of a polysaccharide from the seeds of Borassus flabellifer Linn. Carbohydr Res 1995;277:189-95.

2. Arunachalam K, Saravanan S, Parimelazhagan T. Nutritional analysis and antioxidant activity of palmyrah (Borassus flabellifer L.) seed embryo for potential use as food source. Food Sci Biotechnol 2011;20(1):143-9.

3. Mahesh SP, Swati P, Sachin RP, Ravikumar, Patil MB. Evaluation of the analgesic and antipyretic activities of aqueous-ethanolic extract of male flowers (inflorescences) of Borassus flabellifer L. (Arecaceae). Int J Pharm Pharm Sci 2009;1(2):98-106.

4. Naguleswaran S, Vasanthan T, Hoover R, Liu Q. Structure and physicochemical properties of palmyrah (Borassus flabellifer L.) seed-shoot starch grown in Sri Lanka. Food Chem 2010;118:634-40.

5. Xu Y, Zhang R, Fu H. Studies on the optimal process to extract flavonoids from red-raspberry fruits. J Nat Sci 2005;3(2):43-6.

6. Weirong C, Xiaohong G, Jian T. Extraction, purification, and characterisation of the flavonoids from Opuntia milpa alta Skin. Czech J Food Sci 2010;28(2):108-16.

7. Jorge AJ, Heliodoro de LG, Alejandro ZC, Ruth BC, Noé AC. The optimization of phenolic compounds extraction from cactus pear (Opuntiaficus indica) skin in a reflux system using response surface methodology. Asian Pac J Trop Biomed 2013;3(6):436-42.

8. Fathiazad F, Delazar A, Amiri R, Sarker SD. Extraction of flavonoids and quantification of rutin from waste tobacco leaves. Iran J Pharm Res 2006;3:222-7.

9. Govinda RD, Nagendra SY, Kaladhar DSVGK, Kamalakara RK, Krishna CK. Antibacterial activity of methanolic seed coat extract of Borassus flabellifer L. Int J Pharm Sci Res 2011;2(9):2435-8.

10. Majewska M, Skrzycki M, Podsiad M, Czeczot H. Evaluation of antioxidant potential of flavonoids: An in vitro study. Acta Pol Pharm 2011;68(4):611-5.
11. Nagendra SY, Yothipadmaja I, Rajeswara RP, Surya Kirani KRL, Kaladhar DSVGK, Sai Devi T, et al. In vitro dose dependent study on anti-human pathogenic bacterial and free radical scavenging activities of aqueous-ethanolic seed coat extract of Borassus flabellifer L. Asian J Pharm Clin Res 2012;5(2):83-6.

12. Pramod HJ, Yadav AV, Raje VN, Madhuri M, Ganesh W. Antioxidant activity of Borassus flabellifer Linn.) fruits. AJPTech 2013;3(1):16-9.

13. Sathishkumar T, Baskar R, Shanmugam S, Rajasekaran P, Sadasivam S, Manikandan V. Optimization of flavonoids extraction from the leaves of Tabernaemontana heyneana wall using L16 orthogonal design. J Nat Sci 2008;6(3):1545-40.

14. Prieto P, Pineda M, Aguilar M. Spectrophotometrically quantization of antioxidant capacity through the formation of a phosphomolybdenum complex: specific application to the determination of vitamin E. Anal Biochem 1999;269(2):337-41.

15. Shimada K, Fujikawa K, Nakamura T. Antioxidant properties of xanthan of anti-oxidation of soybean oil in cyclodextrin emulsion. J Agric Food Chem 1992;40:945-8.

16. Cy G, Wang J, Hou Y, Zhao YM, Shen LX, Zhang DS. Orthogonal test design for optimizing the extraction of total flavonoids from Inula helenium. Pharmacogn Mag 2013;9(35):192-5.

17. Chen R, Meng F, Zhang S, Liu Z. Effects of ultrahigh pressure extraction conditions on yields and antioxidant activity of ginsenoside from ginseng. Sep Purif Technol 2009;66(2):340-6.

18. Abe RT. Extraction and isolation of flavonoids present in the aqueous-ethanolic extract of leaves of Acanthospermum hispidium DC. GJMPR 2013;1(1):111-23.

19. Mandal SI, Patra A, Samanta A, Roy S, Mandal A, Mahapatra TD, et al. Analysis of phytochemical profile of Terminalia arjuna bark extract with antioxidant and antimicrobial properties. Asian Pac J Trop Biomed 2013;3(12):960-6. 